\title{
O Brasil na América: duas aproximações
}

\author{
Brazil in America: two approaches
}

\author{
Fernanda Peixoto \\ Doutora em antropologia social pela Universidade de São Paulo (USP) \\ Rua dos Franceses, 470/171 bl. C Bela Vista \\ 01329-010 São Paulo — SP Brasil \\ fpeixoto@uol.com.br
}

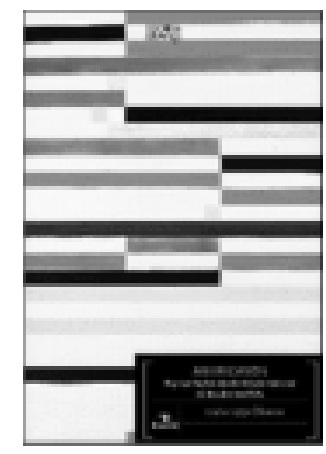

Lúcia Lippi Oliveira Americanos: representações da identidade nacional no Brasil e nos EUA Belo Horizonte, Editora UFMG, 2000, 224p.

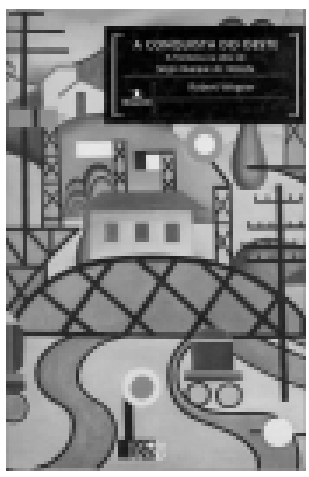

Robert Wegner A conquista do Oeste: a fronteira na obra de Sérgio Buarque de Holanda

Belo Horizonte, Editora da UFMG, 2000, Coleção Humanitas. 275p.
Tuma passagem de entrevista publicada no número 58 da revista Novos Estudos Cebrap (2000), Roberto Schwarz chama a atenção para o "comparativismo congênito" da história literária brasileira, que localiza invariavelmente a literatura produzida entre nós no interior da tradição ocidental mais ampla, conectando, portanto, produção nacional e matrizes européias. Nos trabalhos realizados nas áreas de sociologia e história, por sua vez, continua o crítico, o Brasil parece se esgotar nele mesmo, "como se o que acontecesse aqui dispensasse a consideração do resto" (p. 54). Se a advertência parece procedente em linhas gerais - as nossas ciências sociais, obcecadas pela compreensão do país, driblaram freqüentemente a empresa comparativa e os nexos com a produção internacional -, ela não se aplica a uma série de trabalhos produzidos nos últimos anos, entre os quais figuram $A$ conquista do Oeste: a fronteira na obra de Sérgio Buarque de Holanda, de Robert Wegner, e Americanos: representações da identidade nacional no Brasil e nos EUA, de Lúcia Lippi Oliveira, ambos cuidadosamente editados pela Universidade Federal de Minas Gerais (UFMG). Apesar de seus diferentes formatos e propósitos, os estudos têm, entre outros, o mérito de desprovincianizar a reflexão sobre o país, situando-a num debate ampliado sobre a(s) América(s).

Nesse sentido, a leitura dos volumes, lado a lado, revela-se extremamente proveitosa. Poderíamos dizer que os ensaios reunidos de Lúcia Lippi esboçam um grande painel sobre as relações Brasil-Estados Unidos no seio da qual o estudo de Robert Wegner se abriga ao focalizar estas mesmas relações através da obra de Sérgio Buarque de Holanda. De modo inverso, e complementar, o retrato minucioso pintado por Wegner permite qualificar processos e dimensionar questões apontadas no vasto e elaborado painel traçado por Lippi.

Originalmente tese de doutoramento defendida no Instituto Universitário de Pesquisas do Rio de Janeiro (Iuperj), A conquista do Oeste retoma a já tão estudada obra de Sérgio Buarque de Holanda por meio de seus escritos dos anos 1940 e 1950 sobre as bandeiras, monções e tropeiros, à luz de um problema claramente definido: as concepções do autor sobre as relações entre tradição e modernidade quando da análise da conquista do Oeste brasileiro a partir do planalto paulista. Já na Introdução, Robert Wegner avisa não querer dar conta do conjunto da ampla produção de Sérgio Buarque, muito menos "mapear diálogos, influências ou comparações". Seu intuito é destacar a "face norte-americana" 
dessa obra, inserindo-a assim no debate sobre a história comum das Américas, do qual o historiador se aproxima quando de sua estada nos Estados Unidos, em 1941. Intenções à parte, o fato é que, por meio do exame da noção de fronteira e da relação entre tradição ibérica e modernização - iluminadas pelas querelas da historiografia norteamericana -, o estudo de Wegner traz uma abordagem nova sobre o conjunto da obra de Sérgio Buarque, que desafia as trilhas analíticas mais comumente percorridas.

O livro tem como ponto de partida a consideração dos dilemas da modernização brasileira em Raizes do Brasil, alimentados pelas tensões entre cordialidade e civilidade, ou entre iberismo e americanismo, eixos inconciliáveis neste ensaio de 1936. Na segunda edição do livro, por sua vez - revista após a edição de Monções em 1945 —, observam-se alterações significativas na posição do intérprete que se relacionam à releitura de Max Weber no que diz respeito à formação da mentalidade capitalista e às interpretações em curso sobre a conquista do Oeste brasileiro. Tais mudanças permitem flagrar a insatisfação do autor com explicações de tipo "genético", predominante em Raízes do Brasil, em que o foco da análise recai sobre as "características das tradições transatlânticas" responsáveis pela nossa formação. Nessa direção, a tese defendida por Wegner é que na obra de Sérgio Buarque da segunda metade da década de 1940, "surge uma relação entre tradição ibérica e modernidade na qual estas não são incompatíveis de todo, a ponto de se poder até pensar em um otimismo do autor em relação à modernização da sociedade brasileira através de um caminho promissor e rico, ainda que não isento de problemas" (p. 23).

Fundamentais na demonstração da tese são as partes II e III do livro em que Wegner esboça o ambiente intelectual norte-americano. Nos debates sobre a historiografia do novo continente no período da Grande Guerra, mostra ele, destacam-se reinterpretações que suavizam a dicotomia entre anglo-América e ibero-América e reflexões sobre a singularidade americana, que na obra de Frederick Jackson Turner, por exemplo, é equacionada a partir da idéia de fronteira. A dinâmica da fronteira que a teoria de Turner descreve encontra eco na reflexão de Sérgio Buarque sobre os contornos específicos da vida social originária da conquista do Oeste brasileiro. A leitura detida desses textos do historiador à luz da reflexão de Turner indica que a fronteira em ação traduz um processo acelerado de americanização, conferindo movimento aos valores e crenças relacionados à nossa tradição ibérica. Do ponto de vista metodológico, a marca de Turner se faz notar ainda na opção de Sérgio Buarque por um enfoque "situacional" que reverbera na ênfase por ele conferida à dinâmica transformadora que tem lugar quando da conquista, e que implica a consideração da mescla de tradições díspares.

Se a tradição ibérica é lida como entrave à modernização em Raizes do Brasil, nos trabalhos das décadas de 1940 e 1950, ela aparece dinamizada pela lógica da fronteira e "compatível com um mundo em processo de americanização". A preocupação recorrente na obra de Sérgio Buarque de Holanda com os traços particulares de nosso processo modernizador adquire agora novas configurações. Afastado das polaridades antitéticas sobre as quais se constrói a interpretação de 1936, 
o autor aposta, a partir desse momento, na combinação de tradicionalismo e modernização, de civilidade e cordialidade, de ócio e negócio. "Encontramos agora o negócio valorizado antes que o ócio, mas sem a dispensa absoluta do prazer e do luxo, a conquista do Oeste levada adiante por meio do ajustamento da tradição ao mundo moderno, sem, porém, que isso implique total rendição aos valores ocidentais, ou nos termos de Luiz Werneck Vianna, o americanismo se realizando por intermédio do iberismo" (p. 223).

Tentativas de explicação da América são mapeadas e confrontadas no estudo de Robert Wegner. Elas também atravessam, por outras vias é verdade, os ensaios de Lúcia Lippi. Nos nove estudos que compõem o volume, Américas e americanos somos colocados frente a frente: valores, representações, imaginário, mitos e identidades. Nas palavras da autora, "Americanos: representações da identidade nacional nos Brasil e nos EUA pretende ser menos um estudo sobre os Estados Unidos e mais uma indagação sobre a cultura norte-americana, levada adiante com perguntas produzidas a partir do universo de questões brasileiras. A proposta de estudar as representações da identidade nacional nos Estados Unidos e no Brasil coloca questões desafiadoras, na medida em que estarei trabalhando com valores, símbolos e tradições que pertencem ao universo cultural de cada uma das duas sociedades" (p.10).

A empreitada tem início com a construção do mapa geral dos estudos comparativos entre Brasil e Estados Unidos realizados nos dois países, no campo das ciências sociais e da história (capítulo I). Ao lado da revisão bibliográfica, a autora localiza os intercâmbios institucionais e as políticas culturais, fundamentais para a compreensão dos fluxos e refluxos dessa produção intelectual. Uma vez montada a cena mais ampla, a analista se detém nos ensaios subseqüentes (capítulos II ao VI) no exame de tópicos e autores específicos. Do lado brasileiro, Lúcia Lippi revisita a polêmica entre Richard Morse e Simon Schwartzman como caso exemplar para a discussão das relações entre americanismo e iberismo. Relê também uma certa tradição do pensamento social brasileiro, em função das relações entre sertão e fronteira. Relembra ainda a pouco tratada obra de Viana Moog, Bandeirantes e pioneiros, como momento significativo da análise comparativa entre Brasil e Estados Unidos. Do lado norte-americano, por sua vez, Frederick Turner, Theodore Roosevelt, entre outros, entram em cena para que a intérprete avalie os meandros da construção de uma ideologia nacional, através de mitos fundadores e imagens recorrentes.

Um dos eixos orientadores (e originais) das análises realizadas por Lúcia Lippi acerca dos processos de construção da identidade nacional no Brasil e nos Estados Unidos diz respeito à discussão do espaço geográfico, em que se destacam certas imagens do sertão, a idéia de fronteira, o Oeste e sua conquita. Nesse sentido, afirma a autora, "estive interessada na geografia, mas do ponto de vista da história, tentando tirar a leitura da geografia nacional do espaço da natureza. Minha hipótese de investigação era a de que, nesses dois países, a geografia teria fornecido o mais forte embasamento para a construção dos modelos de identidade nacional que tiveram mais êxito" (p. 11).

Se até esse momento os pontos de contato entre os trabalhos de Robert Wegner e Lúcia Lippi parecem evidentes, nos três capítulos que 
fecham o volume Americanos, a intérprete se afasta da história social das idéias, dos balanços bibliográficos e do inventário das raízes formadoras das identidades nacionais, voltando-se para questões contemporâneas, que extrapolam o interesse acadêmico e interpelam a discussão política e os movimentos sociais, como o multiculturalismo, as migrações e as relações raciais. De qualquer modo, menos do que dois livros num só, é possível perceber o esforço bem-sucedido da autora em mostrar como ecos dos debates intelectuais examinados na primeira parte do volume reverberam na construção de imagens e representações que povoam a vida cotidiana e o senso comum, e que ela enfrenta através da análise das comemorações e feriados como o dia de Ação de Graças ou de uma formatura na Universidade de Brown.

Não seria exagero dizer que, na parte final do livro, a antropóloga se sobrepõe à historiadora das idéias, o que se evidencia nos jogos de estranhamento que a experiência da viagem possibilita e que são registrados nos cadernos de campo, tão caros aos antropólogos e que Lúcia Lippi reedita no capítulo IX: "Tentando vencer as incompreensões", a observadora estrangeira registra episódios corriqueiros, sentimentos e dúvidas sobre a sociedade que visita e, desse modo, lança luz sobre o seu próprio país e sua cultura de origem.

Modernidade e atraso são termos que teimam em aparecer durante o percurso da viagem de Lúcia Lippi. São eles também que fornecem régua e compasso para o roteiro de leitura traçado por Robert Wegner. Estes mesmos tópicos foram destacados por Sérgio Buarque de Holanda em suas "Considerações sobre o americanismo", detidamente analisadas por Robert, e não por acaso citadas por Lúcia Lippi. O tema das relações entre processos de modernização em curso no Brasil e nos Estados Unidos constitui um ponto de interseção entre as três experiências interpretativas. Há vários outros a serem explorados. Convido o leitor a continuar a sondagem. Vale a pena. 